\title{
Immediate improvement of left ventricular mechanics following transcatheter aortic valve replacement
}

\author{
Vanesa Cristina Lozano Granero ${ }^{1}$, Sara Fernández Santos ${ }^{1}$,
}

Covadonga Fernández-Golfín², María Plaza Martín, Jesús María de la Hera Galarza ${ }^{3}$, Francesco Fulvio Faletra ${ }^{4}$, Martin J. Swaans ${ }^{5}$, Teresa López-Fernández ${ }^{6}$, Dolores Mesa ${ }^{7}$, Giovanni La Canna ${ }^{8}$, Tomás Echeverría García ${ }^{9}$, Gilbert Habib ${ }^{10}$, Amparo Martínez Monzonís ${ }^{11}$, José Luis Zamorano Gómez ${ }^{1}$

${ }^{1}$ Cardiology Department, Hospital Universitario Ramón y Cajal, Madrid, Spain; ${ }^{2}$ Cardiology Department, Hospital Universitario Ramón y Cajal, CIBERCV, Madrid, Spain; ${ }^{3}$ Cardiology Department, Hospital Universitario Central de Asturias, Oviedo, Spain; ${ }^{4}$ Division of Cardiology, Cardiocentro Ticino, Lugano,

Switzerland; ${ }^{5}$ Department of Cardiology, St. Antonius Hospital, Nieuwegein, the Netherlands;

${ }^{6}$ Cardiology Department, Hospital Universitario La Paz. IdiPaz, Madrid, Spain;

${ }^{7}$ Cardiology Department, Hospital Universitario Reina Sofía, Córdoba, Spain; ${ }^{8}$ Echocardiography Unit, IRCCS San Raffaele Scientific Institute, Milan, Italy; ${ }^{9}$ Cardiology Department, Hospital Universitario

Donostia, Guipzcoa, Spain; ${ }^{10}$ Cardiology Department, Hôpital de la Timone, Francia;

${ }^{11}$ Complexo Hospitalario Universitario de Santiago, Santiago de Compostela, Spain

\begin{abstract}
Background: Left ventricular (LV) mechanics are impaired in patients with severe aortic stenosis (AS). Transcatheter aortic valve replacement (TAVR) has become a widespread technique for patients with severe AS considered inoperable or high risk for traditional open-surgery. This procedure could have a positive impact in LV mechanics. The aim of this study was to evaluate the immediate effect of TAVR on LV function recovery, as assessed by myocardial deformation parameters.

Methods: One-hundred twelve consecutive patients ( $81.4 \pm 6.4$ years, 50\% female) from 10 centres in Europe with severe AS who successfully underwent TAVR with either a self-expanding CoreValve (Medtronic, Minneapolis, MN) or a mechanically expanded Lotus valve (Boston Scientific, Natick, MA) were enrolled in a prospective multi-center study. A complete echocardiographic examination was performed at baseline and immediately before discharge, including the assessment of $L V$ strain using standard two-dimensional images.

Results: Echocardiographic examination with global longitudinal strain (GLS) quantification could be obtained in 92 patients, because of echocardiographic and logistic reasons. Between examinations, a modest statistically significant improvement in GLS could be seen $(G L S \%-15.00 \pm 4.80$ at baseline; $-16.15 \pm 4.97$ at discharge, $p=0.028$ ). In a stratified analysis, only women showed a significant improvement in GLS and a trend towards greater improvement in GLS according to severity of systolic dysfunction as measured by $L V$ ejection fraction could be noted.

Conclusions: Immediate improvement in GLS was appreciated after TAVR procedure. Whether this finding continues to be noted in a more prolonged follow-up and its clinical implications need to be assessed in further studies. (Cardiol J 2018; 25, 4: 487-494)

Key words: strain, left ventricular mechanics, echocardiography, aortic stenosis, transcatheter aortic valve replacement

Address for correspondence: Dr. Vanesa Cristina Lozano Granero, Cardiology Department. University Hospital Ramon y Cajal, Carretera de Colmenar Viejo, Km 9.100. ZIP: 28034. Madrid, Spain, tel: +34 678690025, fax: +34 913368515, e-mail: cristina.lozano@hotmail.es
\end{abstract}

Received: 21.07.2018 Accepted: 12.06 .2018 


\section{Introduction}

Degenerative aortic stenosis (AS) is one of the most common cardiovascular diseases in developed countries, surpassed only by hypertension and coronary artery disease, and the most frequent valve disease requiring intervention [1], given that valve replacement is the only therapy that improves survival [2]. Over the past decade, transcatheter aortic valve replacement (TAVR) has emerged as a novel therapeutic alternative for patients who are considered inoperable or at high risk for surgery [3, 4].

Aortic stenosis induces a series of adaptive responses to pressure overload that translates in changes in left ventricular (LV) geometry and performance, although LV volume and ejection fraction may remain preserved even in advanced stages of the disease [5]. The most important changes observed include hypertrophic remodeling [6], diastolic dysfunction [7, 8] and impaired contractility [9]. Strain imaging has demonstrated to be the most appropriate method to evaluate the subtle changes in myocardial function that occur in patients with AS $[10,11]$ and global longitudinal strain (GLS), it is also the most useful parameter to independently predict mortality [12]. While improvement in strain parameters has been observed soon after surgical valve replacement $[9,13]$, evidence about the early benefits of TAVR in LV mechanics is scarce. The main objective of this study was to assess the immediate impact of TAVR on strain parameters.

\section{Methods}

\section{Study population}

This is a prospective cohort study conducted at ten centres in Europe. All patients with symptomatic severe AS undergoing TAVR with either a self-expanding CoreValve system (Medtronic, Minneapolis, MN) or a mechanically expanded Lotus valve (Boston Scientific, Natick, MA) were eligible. Exclusion criteria included: poor echocardiographic window (defined as two or more inadequately visualized myocardial segments [considering a 17-segment model]), the presence of atrial fibrillation (AF) at the initial evaluation, the existence of an unstable cardiac condition (such as an acute coronary syndrome or significant pericardial effusion) or refusal to provide written informed consent. The patients were evaluated at two points in time, prior to the procedure, generally between 24 and $48 \mathrm{~h}$ before the implant (visit 1 or V1), and on the planned discharge day (visit 2 or V2). The study was approved by our ethics committee and endorsed by the different committees at each participant center.

\section{Demographic and clinical data}

Collected variables regarding demographic and clinical data included age, sex, height, weight, body surface area, body mass index and New York Heart Association functional class. Comorbidities were obtained from a medical interview or by reviewing medical charts, and included hypertension, diabetes, myocardial infarction, cerebrovascular disease, peripheral artery disease, and severe pulmonary obstructive disease.

\section{Two-dimensional echocardiography}

Echocardiographic examinations were performed using available imaging equipment at each center, provided that the same machine was used for all the examinations of any given patient. The imaging devices employed include: Vivid E9 (GE Medical systems, Horten, Norway), iE33, HD11, EPIQ7 (Philips Medical Systems, Bothell, WA, USA) and Acuson S2000 (Siemens Medical Solution, Mountain view USA). The LV end-diastolic and end-systolic volume were obtained at the standard apical 4-chamber and 2-chamber views, LV ejection fraction (LVEF) was calculated using the Simpson method. GLS was computed from the apical 4-chamber, 2-chamber and 3-chamber views. Endocardial borders were traced by hand at an end-systolic and/or end-systolic frame, according to the vendor, and myocardial speckles were automatically tracked throughout subsequent frames. Whenever necessary, tracking was manually corrected. GLS was obtained as the average value of regional strains. Absolute increase and percentage change in GLS was calculated between V1 and V2.

\section{Statistical analysis}

Continuous variables were tested for normality of distribution with the Saphiro-Wilk test. Data is presented as mean \pm standard deviation when normally distributed or median (interquartile range). The paired t test and Wilcoxon signed-rank test were used to compare pre- and post-procedural quantitative parameters. Categorical data were presented as numbers (percentages) and compared with the Pearson $\chi^{2}$ test when appropriate. P values $<0.05$ were considered significant. All statistical analyses were performed using Stata 13.0 (StataCorp LLC, College Station, Texas). 


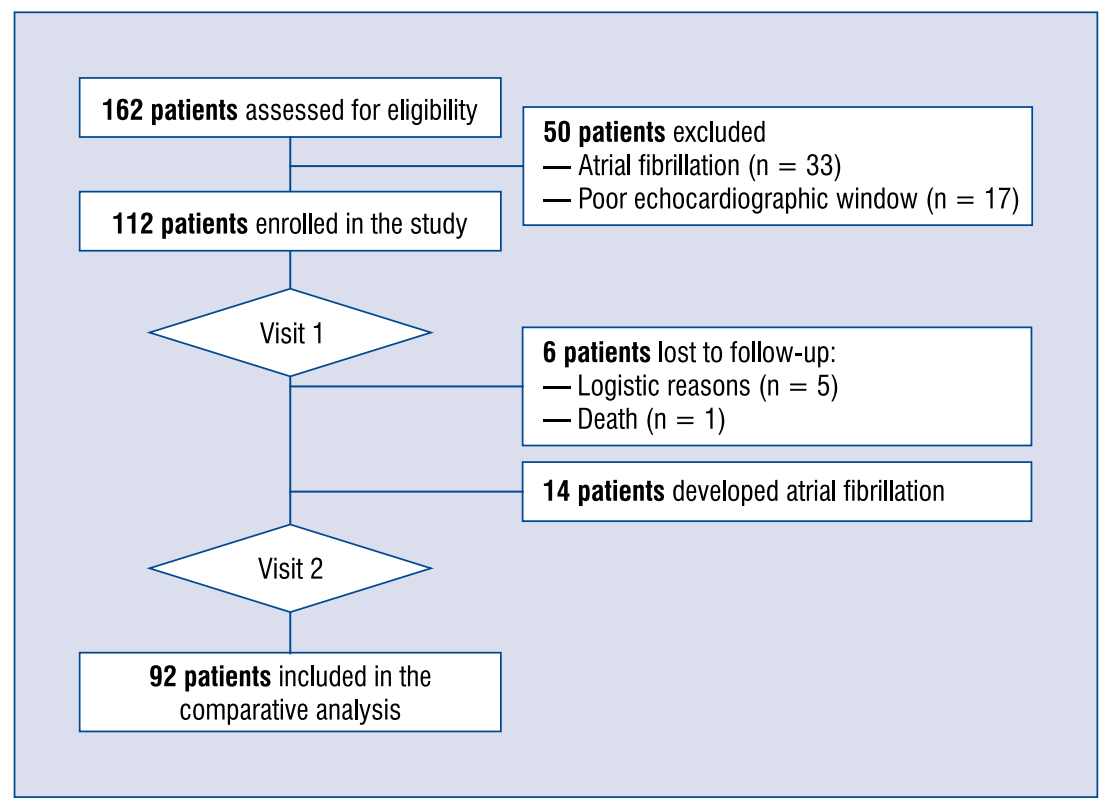

Figure 1. Patient flow chart.

\section{Results}

\section{Patient characteristics}

The patient flow chart is presented in Figure 1. A total of 172 patients who underwent TAVR at participant centres were assessed for eligibility. Sixty $(35 \%)$ patients met the exclusion criteria, 40 due to the presence of $\mathrm{AF}$ at the initial evaluation and 20 because of poor echocardiographic window, and were not enrolled in the study. Among the 112 patients included, $6(5.4 \%)$ patients were lost to follow up: 5 lacked a complete pre-discharge echocardiographic examination because of logistical reasons (i.e. prompt return to the reference hospital), and 1 died shortly after intervention. Finally, 14 patients had developed $\mathrm{AF}$ at the discharge analysis (including patients with a prior diagnostic of paroxysmal $\mathrm{AF}$ as well as new-onset $\mathrm{AF}$ ), leaving a population of 92 patients for comparative analysis.

Patient baseline characteristics are summarized in Table 1. Concerning demographic and clinical variables among the 112 patients included, $50 \%$ were female and $81.4 \pm 6.4$ years old, $76 \%$ had hypertension, $23 \%$ had diabetes mellitus, $16 \%$ had history of coronary artery disease, and $11 \%$ showed areas of scarred LV tissue.

All 112 patients had severe AS: mean value for aortic valve area (AVA) was $0.74 \pm 0.22 \mathrm{~cm}^{2}$ and mean pressure gradient was $46 \pm 15 \mathrm{mmHg}$. A reduced LVEF of $50 \%$ or less was seen in 31 of 112 patients (28\%) and paradoxical low-flow state (LVEF $>50 \%$ and stroke volume index $<35 \mathrm{~mL} / \mathrm{m}^{2}$ )
Table 1. Baseline characteristics.

\begin{tabular}{lc}
\hline Variable & Value \\
\hline Demographic and clinical variables & \\
Age [years] & $81.4 \pm 6.4$ \\
Female & $56(50 \%)$ \\
Body surface area [m $\left.^{2}\right]$ & $1.73 \pm 0.19$ \\
Body mass index $\left[\mathrm{kg} / \mathrm{m}^{2}\right]$ & $26.48 \pm 4.38$ \\
Hypertension & $72(76 \%)$ \\
Diabetes mellitus & $38(25 \%)$ \\
Coronary artery disease & $15(16 \%)$ \\
NYHA class II-IV & $104(93 \%)$ \\
Aortic valve severity & \\
Aortic valve area [cm $\left.{ }^{2}\right]$ & $0.74 \pm 0.22$ \\
Indexed aortic valve area $\left[\mathrm{cm}^{2} / \mathrm{m}^{2}\right]$ & $0.44 \pm 0.17$ \\
Mean pressure gradient $[\mathrm{mmHg}]$ & $46.12 \pm 15.34$ \\
Peak pressure gradient $[\mathrm{mmHg}]$ & $76 \pm 27$ \\
Geometry and systolic function & \\
LV ejection fraction $[\%]$ & $56 \pm 12.2$ \\
LV end-diastolic volume $\left[\mathrm{mL}^{2}\right]$ & $98.1 \pm 36.6$ \\
Stroke volume [mL/m $\left.{ }^{2}\right]$ & $67.5 \pm 22.9$ \\
Indexed mass $\left[\mathrm{g} / \mathrm{m}^{2}\right]$ & $145.4 \pm 46.1$ \\
\hline
\end{tabular}

LV — left ventricular; NYHA — New York Heart Association

was seen in 27 of 112 patients (24\%). Indexed LV mass was $145 \pm 46 \mathrm{~g} / \mathrm{m}^{2}$, with $75(67 \%)$ patients having significant LV hypertrophy (considering $\geq 132 \mathrm{~g} / \mathrm{m}^{2}$ for men and $\geq 109 \mathrm{~g} / \mathrm{m}^{2}$ in women as the cut-off for moderate hypertrophy). 
Table 2. Results of echocardiographic parameters of aortic stenosis severity, left ventricular (LV) geometry, LV systolic function and LV mechanics.

\begin{tabular}{lccc} 
& & V2 & P \\
\hline Aortic stenosis severity parameters & & & $<0.0001$ \\
Aortic valve area $\left[\mathrm{cm}^{2}\right]$ & $0.73 \pm 0.22$ & $1.92 \pm 0.6$ & $<0.0001$ \\
Indexed aortic valve area $\left[\mathrm{cm}^{2} / \mathrm{m}^{2}\right]$ & $0.43 \pm 0.17$ & $1.10 \pm 0.036$ & $<0.0001$ \\
Mean pressure gradient $[\mathrm{mmHg}]$ & $47 \pm 15$ & $12 \pm 8$ & $<0.0001$ \\
Peak pressure gradient & $78 \pm 26$ & $22 \pm 13$ & 0.0008 \\
LV geometry, systolic function and mechanics parameters & & $130 \pm 38$ \\
LV indexed mass $\left[\mathrm{g} / \mathrm{m}^{2}\right]$ & $145 \pm 47$ & $57 \pm 11$ & 0.1069 \\
LV ejection fraction $(\mathrm{Simpson}$ method) $[\%]$ & $56 \pm 12$ & $68 \pm 23$ & 0.8136 \\
Stroke volume $\left[\mathrm{mL} / \mathrm{m}^{2}\right]$ & $68 \pm 24$ & $-16.2 \pm 5.1$ & 0.0057 \\
Global longitudinal strain $[\%]$ & $-14.9 \pm 5.0$ & & \\
\hline
\end{tabular}

$\mathrm{V} 1$ - baseline; $\mathrm{V} 2$ - after the procedure

Evolution of AS severity, LV mass

and function and myocardial

deformation parameters

The first echocardiographic examination (V1) was performed a median of 1 day $[1,2]$ prior to intervention and the second took place a median of 5 days [4-7] after the procedure.

The echocardiographic parameters measured at baseline (V1) and after the procedure (V2) are listed in Table 2.

Predictably, parameters of AS severity suffered a profound change after TAVR procedure, with a statistically significant increase in AVA (from $0.73 \pm 0.22 \mathrm{~cm}^{2}$ to $1.92 \pm 0.6 \mathrm{~cm}^{2}, \mathrm{p}<0.0001$ ) and a significant decrease in transvalvular gradients (mean gradient from $47 \pm 15 \mathrm{mmHg}$ to $12 \pm 8$ mmHg, $\mathrm{p}<0.0001$; peak gradient from $78 \pm 26$ $\mathrm{mmHg}$ to $22 \pm 13 \mathrm{mmHg}, \mathrm{p}<0.0001$ ).

Regarding LV geometry, systolic function and mechanics, a significant decrease in LV mass was noted (from $145 \pm 47 \mathrm{~g} / \mathrm{m}^{2}$ to $130 \pm 38 \mathrm{~g} / \mathrm{m}^{2}, \mathrm{p}=$ $=0.0008$ ) while systolic function remained globally unaltered, as statistically significant changes could not be seen in LVEF with the Simpson biplane method $(56 \pm 12 \%$ in $\mathrm{V} 1$ and $57 \pm 11 \%$ in $\mathrm{V} 2, \mathrm{p}=$ $=0.1069)$ and in $\mathrm{LV}$ stroke volume $\left(68 \pm 24 \mathrm{~mL} / \mathrm{m}^{2}\right.$ in $\mathrm{V} 1$ and $68 \pm 23 \mathrm{~mL} / \mathrm{m}^{2}$ in $\left.\mathrm{V} 2, \mathrm{p}=0.8136\right)$. Nevertheless, when stratified by basal LVEF (considering normal LVEF values those $>50 \%$ and abnormal those $\leq 50 \%$ ), a modest improvement in this parameter could be noted in the group of patients with previous abnormal LVEF (from $40 \pm 8 \%$ in $\mathrm{V} 1$ to $44 \pm 11 \%$ in $\mathrm{V} 2, \mathrm{p}=0.0343$ ) and not in those with previous normal LVEF (from $62 \pm 7 \%$ in V1 to $63 \pm 8 \%$ in $\mathrm{V} 2, \mathrm{p}=0.6771)$. In contrast, GLS was significantly lower after the procedure $-14.9 \pm$

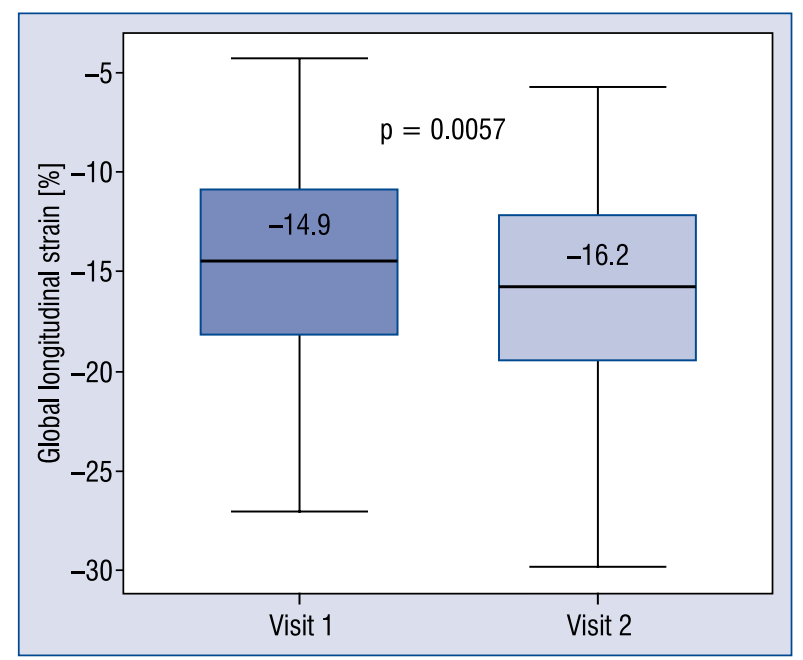

Figure 2. Box plots representing global longitudinal strain at each visit.

$\pm 5.0 \%$ in $\mathrm{V} 1$ and $-16.2 \pm 5.1 \%$ in $\mathrm{V} 2, \mathrm{p}=0.0057$ ).

Figure 2 presents box plots of GLS at each visit.

\section{LV mechanics improvement according to demographic characteristics}

In subgroup analysis considering demographic characteristics, a significant improvement in LV mechanics could only be seen in female patients, with an absolute increase of $1.8 \%$ in GLS between examinations in the female population (GLS $-15.3 \pm 4.49 \%$ at $\mathrm{V} 1$ and $-17.1 \pm 4.74 \%$ at $\mathrm{V} 2$, $\mathrm{p}=0.0061$ ) and $0.66 \%$ in the male population (GLS $-14.7 \pm 5.08 \%$ at $\mathrm{V} 1$ and $-15.3 \pm 4.93 \%$ at V2, $\mathrm{p}=0.2525)$. Figure 3 presents box plots of GLS at each visit for each sex category. No other 


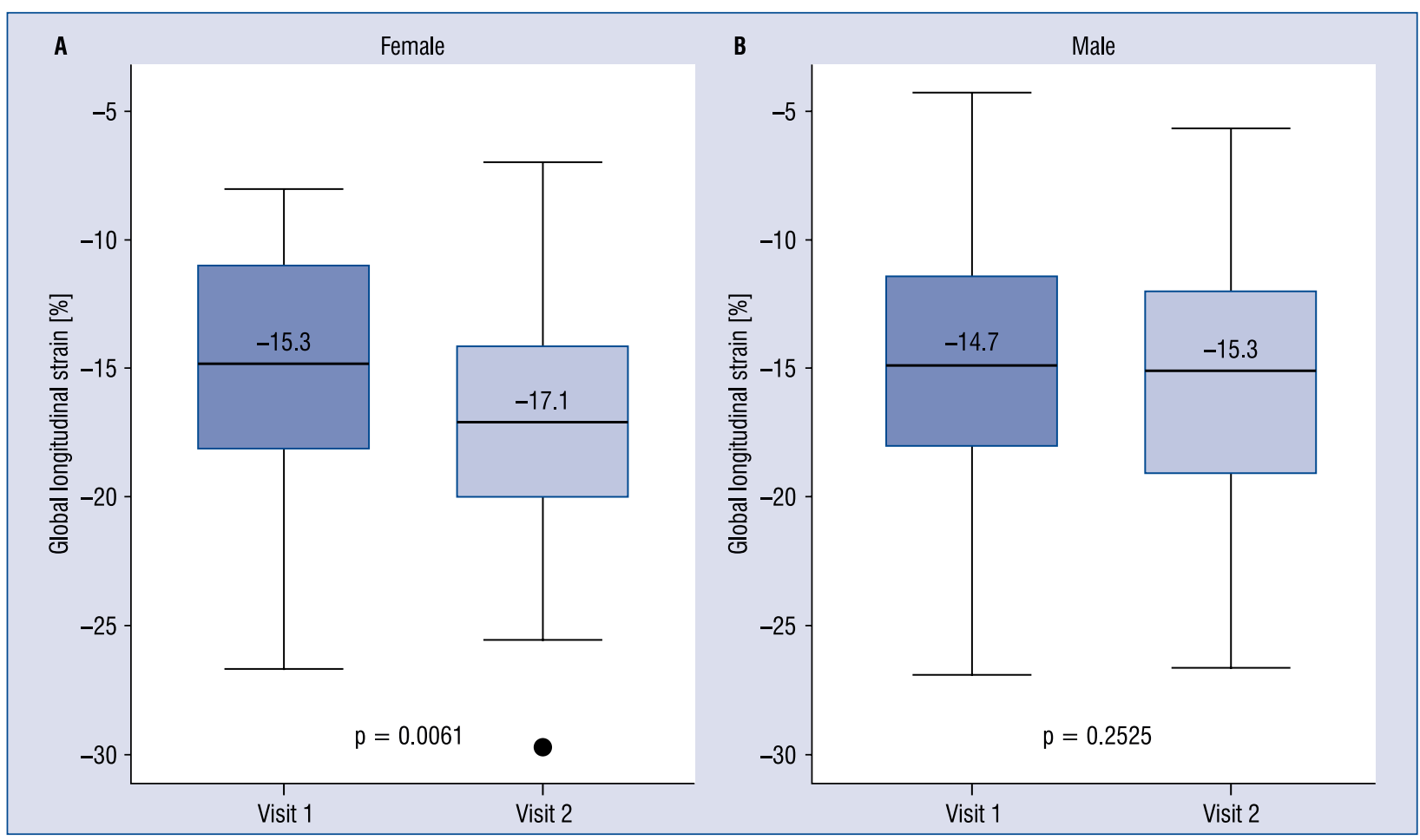

Figure 3. Box plots representing global longitudinal strain at each visit for each sex category. A. Female; B. Male.

differences could be seen in AS severity or LV systolic function parameters between sex categories.

\section{LV mechanics improvement according to $\mathrm{LV}$ characteristics}

When stratified according to LV systolic function by LVEF (Simpson Biplane method), those with reduced systolic function, defined as an LVEF of less than $50 \%, \mathrm{n}=24$, experienced a greater improvement in GLS (from $-11.1 \pm 4.3 \%$ to $-12.6 \pm 4.3, \mathrm{p}=0.0152$ ), than those with a preserved systolic function, defined as an LVEF of $50 \%$ or superior, $\mathrm{n}=68$ (from $-16.3 \pm 4.5 \%$ to $-17.4 \pm 4.7 \%, \mathrm{p}=0.0473)$. Considering different degrees of systolic dysfunction (with mild systolic dysfunction defined as an LVEF between $40 \%$ to $49 \%$, $\mathrm{n}=12$; moderate systolic dysfunction as an LVEF between $30 \%$ to $39 \%, \mathrm{n}=8$; and severe systolic dysfunction as and LVEF inferior to $30 \%, \mathrm{n}=4$ ), improvement in GLS was proportional to systolic dysfunction, with the greatest improvement in the group with severe systolic dysfunction, although statistical significance was not achieved in all categories, probably because of an insufficient number of subjects in each (from $-12.9 \pm 4.1 \%$ in $\mathrm{V} 1$ to $-14.1 \pm 3.8 \%$ in $\mathrm{V} 2, \mathrm{p}=0.2202$, in mild systolic dysfunction; from $-9.6 \pm 2.6 \%$ in V1 to $-11.1 \pm 4.3 \%$ in $\mathrm{V} 2, \mathrm{p}=0.1821$, in moderate sys- tolic dysfunction; and from $-6.0 \pm 2.6 \%$ in $\mathrm{V} 1$ to $-9.0 \pm 3.7 \%$ in $\mathrm{V} 2, \mathrm{p}=0.0418$, in severe systolic dysfunction). Figure 4 presents box plots of GLS at each visit for each category of systolic function. In the subset of patients showing areas of scarred LV tissue $(n=12)$, a greater GLS improvement could be noted compared to those without scarred tissue (from $-10.4 \pm 2.7 \%$ to $-12.9 \pm 2.8 \%, \mathrm{p}=0.1622$ in patients with presence of scar compared to $-15.7 \pm 4.8 \%$ to $-17.2 \pm 4.9 \%, \mathrm{p}=0.036$ ), although statistical significance was not reached, probably due to the small size of this subgroup.

\section{LV mechanics improvement according to type of valve}

When analyzed separately, only the group receiving a self-expanding valve showed a statistically significant improvement in GLS at this point in time; from $-15.4 \pm 4.8 \%$ to $-18.3 \pm 5.2 \%$ in the self-expanding valve group $(\mathrm{p}=0.0002)$; from $-15.2 \pm 5.0 \%$ to $-15.8 \pm 4.5 \%$ in the mechanicallyexpanded valve group $(\mathrm{p}=0.3595)$. No difference could be seen in the improvement in mean and peak gradients or in the AVA after the procedure: mean gradient from $52 \pm 13 \mathrm{mmHg}$ to $10 \pm 10 \mathrm{mmHg}$ in the self-expanding valve group $(\mathrm{p}<0.0001)$, from $43 \pm 15 \mathrm{mmHg}$ to $13 \pm 6 \mathrm{mmHg}$ in the mechanically-expanded valve $(\mathrm{p}<0.0001)$; peak 


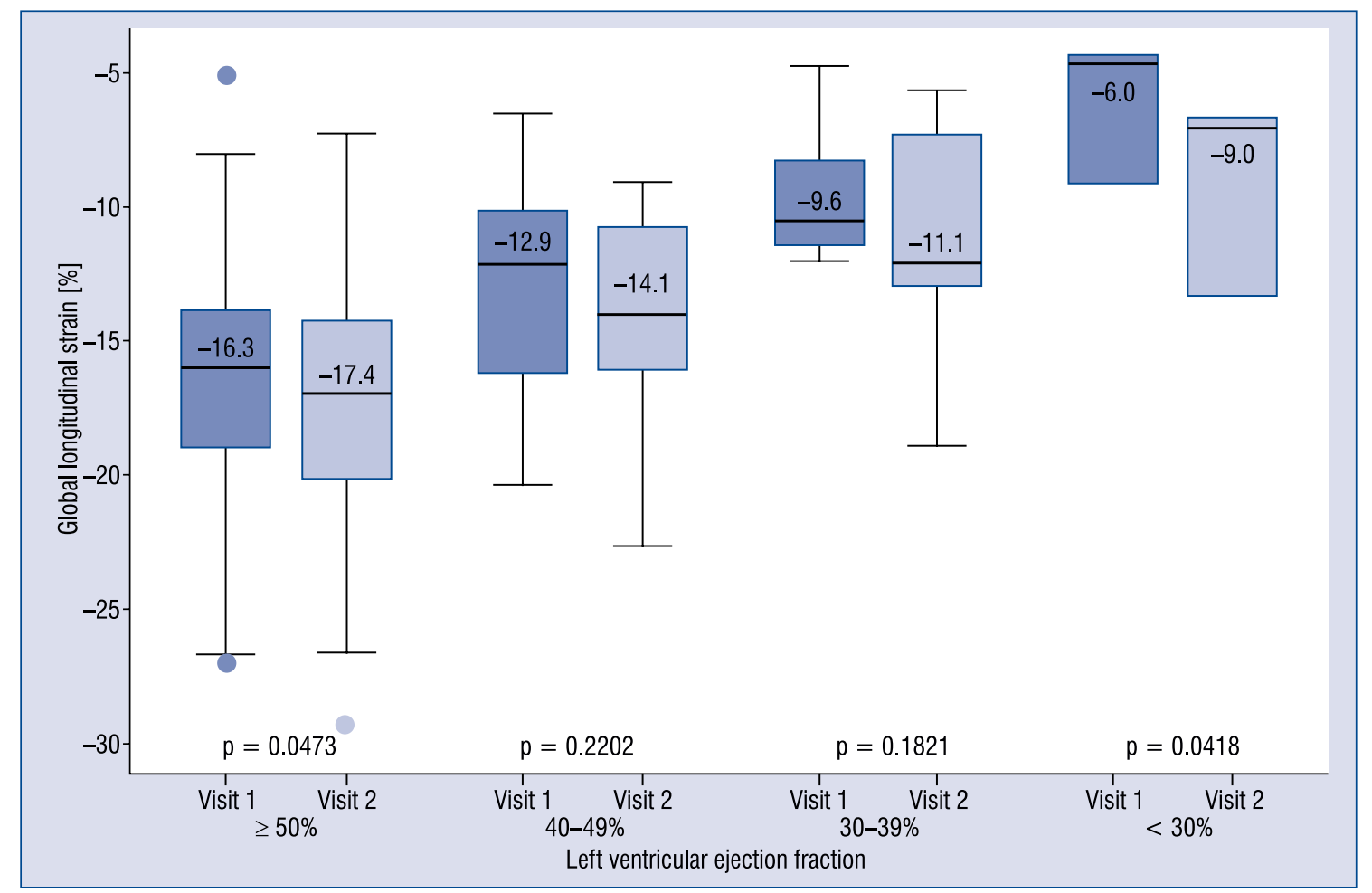

Figure 4. Box plots representing global longitudinal strain at each visit for each systolic function category.

gradient from $88 \pm 28 \mathrm{mmHg}$ to $18 \pm 16 \mathrm{mmHg}$ in the self-expanding valve group $(\mathrm{p}<0.0001)$, from $71 \pm 22 \mathrm{mmHg}$ to $23 \pm 11 \mathrm{mmHg}$ in the mechanically-expanded valve $(\mathrm{p}<0.0001)$; AVA from $0.7 \pm$ $\pm 0.2 \mathrm{~cm}^{2}$ to $2.1 \pm 0.7 \mathrm{~cm}^{2}$ in the self-expanding valve group $(\mathrm{p}<0.0001)$, from $0.8 \pm 0.2 \mathrm{~cm}^{2}$ to $1.8 \pm 0.6 \mathrm{~cm}^{2}$ in the mechanically-expanded valve group $(\mathrm{p}<0.0001)$. However, a difference could be seen in LV systolic function using the Simpson biplane method between the two types of prosthesis, with only the self-expanding prosthesis achieving a significant increment (from $57 \pm$ $\pm 10 \mathrm{~cm}^{2}$ to $60 \pm 10 \mathrm{~cm}^{2}$ in the self-expanding valve group ( $\mathrm{p}=0.0123$ ), from $56 \pm 13 \mathrm{~cm}^{2}$ to $56 \pm 13 \mathrm{~cm}^{2}$ in the mechanically-expanded valve group $(\mathrm{p}=0.7380)$.

\section{Discussion}

The main findings of this study are as follow: (i) TAVR is associated with an immediate improvement in LV mechanics, as demonstrated by GLS increase, (ii) this occurs although LV systolic function, as assessed by LVEF or stroke volume, remains unaltered, (iii) this improvement is restricted to women and (iv) shows a trend toward being directly proportional to the degree of systolic dysfunction.

\section{Patient population}

It was considered that the population included in the present study accurately represents that of severe AS patients usually referred for TAVR procedure, and have similar characteristics to the population included in the intermediate-risk patient study [14].

\section{Reverse remodeling in TAVR}

Severe AS causes a chronic pressure overload that leads to pathologic remodeling in the form of concentric hypertrophy, with an increase in LV mass that results in an impaired diastolic function and a mostly preserved systolic function, although LV mechanics are usually impaired. TAVR causes an acute decrease in transvalvular gradient that could lead to an immediate improvement in LV mechanics, which could be a precursor of reverse remodeling, which in turn could lead to a reduction in $\mathrm{LV}$ mass and improvement in diastolic function in the long term. In this study, the observations which were restricted to the first days after TAVR, no change was noted in systolic function as assessed by LVEF through the Simpson biplane method, was largely normal prior to the procedure, but an otherwise significant increase in GLS was seen. In a considered opinion, this could represent the first landmark of an incipient reverse remodeling. 
An immediate reduction in indexed LV mass was also seen, a finding also seen in previous studies, both with TAVR and surgical replacement [15-17]. A correlation between time of performance of the second echocardiographic examination and LV mass reduction could not be found $(p=0.1772)$. Given that this change could hardly be explained by changes in myocyte size or number, protein synthesis, organization of the sarcomere or fibrosis, it was proposed that this change could represent a reduction in myocardial edema, as seen in myocarditis [18].

In a stratified analysis according to gender, only female patients experienced a significant improvement in GLS. This finding is in line with other published studies suggesting that women may have better outcomes with TAVR that men, the nature of this association remains unknown [19].

In stratified analysis by LVEF, a strong trend could be noted towards a greater increase in GLS in patients with more severe dysfunction. Although only those with preserved ejection fraction or severe dysfunction experienced a statistically significant improvement in GLS, failure to find statistically significant differences in mild and moderate impaired systolic function subcategories was likely due to a consequence of the small sample size of these subgroups. The finding of improvement in LV mechanics even once systolic dysfunction has been established could be a manifestation of reversible adverse LV remodeling, which would encourage the use of TAVR in this kind of patient.

In stratified analysis according to valve subtype, only the group receiving a self-expanding valve showed a statistically significant improvement in GLS at this point in time. While both kinds of valve showed similar changes in transaortic gradients and AVA after the procedure, the group receiving the self-expanding valve achieved a statistically significant improvement in LV systolic function as assessed by the Simpson biplane method, which could in turn explain the difference in GLS improvement. Although previous studies have also shown an early improvement in LV systolic function with the self-expanding valve [20], the reason for this difference in early LV mechanic behaviour remains unclear and should be clarified in further studies.

\section{Limitations of the study}

The main limitation of the study was the use of different cardiac ultrasound machines and vendor-specific software in participant centers, which make absolute values of GLS for each visit non-comparable between participants of different centers. However, given that the same machine and software was used in each visit in any given patient, it was believed the change in GLS was comparable between participants of different centers.

Radial and circumferential strain values were not collected in the study, mainly because GLS was more widespread and reproducible, and was considered to be a more relevant parameter of $\mathrm{LV}$ mechanics for clinical application. Thus, potential changes in radial and circumferential deformation could not be studied.

\section{Conclusions}

Although systolic function remained unaltered immediately after TAVR, an improvement in GLS could be appreciated soon after the procedure. This was found to occur only in women and be greater in patients with systolic dysfunction, although the present study lacks sufficient sample size to find a statistically significant difference in the small group of patients with impaired LVEF. Whether this finding continues to be noted in a more prolonged follow-up and its clinical implications need to be assessed in further studies.

\section{Acknowledgements}

This study was supported by a non-conditioned grant from Boston Scientific, Natick, MA, USA.

\section{Conflict of interest: None declared}

\section{References}

1. Nkomo VT, Gardin JM, Skelton TN, et al. Burden of valvular heart diseases: a population-based study. Lancet. 2006; 368(9540): 1005-1011, doi: 10.1016/S0140-6736(06)69208-8, indexed in Pubmed: 16980116.

2. Schwarz F, Baumann P, Manthey J, et al. The effect of aortic valve replacement on survival. Circulation. 1982; 66(5): 1105-1110, indexed in Pubmed: 7127696.

3. Leon MB, Smith CR, Mack M, et al. PARTNER Trial Investigators. Transcatheter aortic-valve implantation for aortic stenosis in patients who cannot undergo surgery. N Engl J Med. 2010; 363(17): 1597-1607, doi: 10.1056/NEJMoa1008232, indexed in Pubmed: 20961243.

4. Smith C, Leon M, Mack M, et al. Transcatheter versus Surgical Aortic-Valve Replacement in High-Risk Patients. N Engl J Med. 2011; 364(23): 2187-2198, doi: 10.1056/nejmoa1103510.

5. Ross J. Afterload mismatch and preload reserve: a conceptual framework for the analysis of ventricular function. Prog Cardiovasc Dis. 1976; 18(4): 255-264, indexed in Pubmed: 128034.

6. Gerdts E. Left ventricular structure in different types of chronic pressure overload. Eur Heart J Suppl. 2008; 10(suppl_E): E23-E30, doi: 10.1093/eurhearti/sun015. 
7. Chang SA, Park PW, Sung K, et al. Noninvasive estimate of left ventricular filling pressure correlated with early and midterm postoperative cardiovascular events after isolated aortic valve replacement in patients with severe aortic stenosis. J Thorac Cardiovasc Surg. 2010; 140(6): 1361-1366, doi: 10.1016/j. jtcvs.2010.02.022, indexed in Pubmed: 20381086.

8. Dahl J, Videbæk L, Poulsen M, et al. Noninvasive assessment of filling pressure and left atrial pressure overload in severe aortic valve stenosis: Relation to ventricular remodeling and clinical outcome after aortic valve replacement. J Thorac Cardiovasc Surg. 2011; 142(3): e77-e83, doi: 10.1016/j.jtcvs.2011.01.032.

9. Delgado V, Tops LF, van Bommel RJ, et al. Strain analysis in patients with severe aortic stenosis and preserved left ventricular ejection fraction undergoing surgical valve replacement. Eur Heart J. 2009; 30(24): 3037-3047, doi: 10.1093/eurheartj/ehp351, indexed in Pubmed: 19726436.

10. Weidemann F, Jamal F, Sutherland GR, et al. Myocardial function defined by strain rate and strain during alterations in inotropic states and heart rate. Am J Physiol Heart Circ Physiol. 2002; 283(2): H792-H799, doi: 10.1152/ajpheart.00025.2002, indexed in Pubmed: 12124229.

11. Weidemann F, Jamal F, Kowalski M, et al. Can strain rate and strain quantify changes in regional systolic function during dobutamine infusion, B-blockade, and atrial pacing--implications for quantitative stress echocardiography. J Am Soc Echocardiogr. 2002; 15(5): 416-424, indexed in Pubmed: 12019424.

12. Kusunose K, Goodman A, Parikh R, et al. Incremental prognostic value of left ventricular global longitudinal strain in patients with aortic stenosis and preserved ejection fraction. Circulation: Cardiovascular Imaging. 2014; 7(6): 938-945, doi: 10.1161/circimaging.114.002041.

13. Chen Y, Zhang $Z$, Cheng L, et al. The early variation of left ventricular strain after aortic valve replacement by three-dimensional echocardiography. PLoS One. 2015; 10(10): e0140469, doi: 10.1371/journal.pone.0140469, indexed in Pubmed: 26473730.
14. Leon M, Smith C, Mack M, et al. Transcatheter or Surgical Aortic-Valve Replacement in Intermediate-Risk Patients. N Engl J Med. 2016; 374(17): 1609-1620, doi: 10.1056/nejmoa1514616.

15. Douglas PS, Hahn RT, Pibarot P, et al. Hemodynamic outcomes of transcatheter aortic valve replacement and medical management in severe, inoperable aortic stenosis: a longitudinal echocardiographic study of cohort B of the PARTNER trial. J Am Soc Echocardiogr. 2015; 28(2): 210-217.e1, doi: 10.1016/j. echo.2014.10.009, indexed in Pubmed: 25455544.

16. Dobson LE, Musa TA, Uddin A, et al. Acute reverse remodelling after transcatheter aortic valve implantation: a link between myocardial fibrosis and left ventricular mass regression. Can J Cardiol. 2016; 32(12): 1411-1418, doi: 10.1016/j. cjca.2016.04.009, indexed in Pubmed: 27523272.

17. Shin S, Park PW, Han WS, et al. Mass reduction and functional improvement of the left ventricle after aortic valve replacement for degenerative aortic stenosis. Korean J Thorac Cardiovasc Surg. 2011; 44(6): 399-405, doi: 10.5090/kjtcs.2011.44.6.399, indexed in Pubmed: 22324024.

18. Zagrosek A, Wassmuth R, Abdel-Aty H, et al. Relation between myocardial edema and myocardial mass during the acute and convalescent phase of myocarditis--a CMR study. J Cardiovasc Magn Reson. 2008; 10: 19, doi: 10.1186/1532-429X-10-19, indexed in Pubmed: 18447954.

19. Humphries KH, Toggweiler S, Rodés-Cabau J, et al. Sex differences in mortality after transcatheter aortic valve replacement for severe aortic stenosis. J Am Coll Cardiol. 2012; 60(10): 882-886, doi: 10.1016/j.jacc.2012.05.009, indexed in Pubmed: 22818068.

20. Dauerman HL, Reardon MJ, Popma JJ, et al. Early recovery of left ventricular systolic function after corevalve transcatheter aortic valve replacement. Circ Cardiovasc Interv. 2016; 9(6), doi: 10.1161/CIRCINTERVENTIONS.115.003425, indexed in Pubmed: 27296201. 